\title{
Standardization and validation of Dot-ELISA assay for Paracoccidioides brasiliensis antibody detection
}

\author{
Camila Mika Kamikawa ${ }^{1,2}$, Rinaldo Poncio Mendes ${ }^{3}$ and Adriana Pardini Vicentini ${ }^{1,2^{*}}$
}

\begin{abstract}
Background: Paracoccidioidomycosis (PCM) is a neglected systemic mycosis caused by a dimorphic fungus of the Paracoccidioides genus. The standard diagnosis is based on isolation of the fungi in culture, and by microscopic visualization of characteristic multiple budding yeast cells in biological samples. However, in some situations, access to the site of injury prevents the collection of biological material. A variety of immuno-serological techniques has proven useful for allowing inferring diagnosis with a certain degree of certainty, thus optimizing time. The aim of this study was to standardize and validate the Dot-ELISA (DE) assay, comparing it with the serological standard, double immunodiffusion (DI).

Methods: In order to standardize the DE assay, 143 serum samples were used. Out of those, 23 were from apparently healthy patients, 77 were from patients with confirmed PCM and 43 were from patients with other lung infections (tuberculosis, aspergillosis and histoplasmosis). To validate the DE technique, 300 serum samples from patients with PCM clinical suspicion (probable and possible cases) were employed, and these results were compared with those of DI.
\end{abstract}

Results: The DE assay showed sensitivity of $91 \%$, specificity of $95.4 \%$, positive predictive value of $96 \%$, negative predictive value of $98.2 \%$, accuracy of $93 \%$, and great precision ( $k=0.93$ ). In addition, the nitrocellulose membranes have proved to be viable for using at least 90 days after $P$. brasiliensis B-339 antigen sensitization.

Conclusion: Dot-ELISA method was found to be an extremely promising tool as serologic screening technique, because of its high sensitivity. Furthermore, Dot-ELISA shows the prospect of being transferred to laboratories of mycoserology including those with fewer resources or even to be used directly in the field. It has an excellent shelf life - membranes coated with antigen can be used for testing without changes in the pattern of reactivity among laboratories - and presents reliable values of sensitivity, specificity, predictive values, accuracy and a high correlation with the serological standard methodology. Based on the present findings, it possible to state that this technique constitutes a remarkable option to be used in routine diagnosis for public health centers.

Keywords: Paracoccidioidomycosis, Paracoccidioides brasiliensis, Immunodiagnostic tool, Dot-ELISA, Validation

\footnotetext{
*Correspondence: dricavicentini@gmail.com; apardini@ial.sp.gov.br

${ }^{1}$ Laboratory of Mycosis Immunodiagnosis, Center of Immunology, Adolfo

Lutz Institute, Av. Dr. Arnaldo, 355, 110 andar, sala 1117 São Paulo, SP, Brazil

${ }^{2}$ Graduate Program in Sciences, Disease Control Coordination of the São

Paulo State Health Secretariat, São Paulo, SP, Brazil

Full list of author information is available at the end of the article
} 


\section{Background}

Paracoccidioidomycosis (PCM) is the most important systemic mycosis of Latin America caused by the thermally dimorphic fungus Paracoccidioides spp. [1-4]. Endemic areas extends from Argentina to Central America; however, approximately $80 \%$ of PCM cases, especially due to Paracoccidioides brasiliensis, have been reported in Brazil $[1,5]$. In Brazil, the disease is considered the eighth cause of death among infectious and parasitic diseases, presenting a mortality rate of 1.4 per million inhabitants [6]. PCM presents a wide spectrum of clinical manifestations and it is more frequent in males than in females (a ratio of approximately 7.2:1) and affects people from 30 to 60 years old, mainly the ones living in rural areas [7-9].

The definitive diagnosis of $P$. brasiliensis infection consists in the direct microscopic examination of biological specimens and their culturing followed by macro and microscopic observation for the fungus identification $[10,11]$. However, serological techniques are usually simpler than culture and are employed in early diagnosis of PCM, they are also useful for monitoring its evolution and response to treatment [3, 10-14].

Among different serological assays, double immunodiffusion (DI) is the standard method used for the diagnosis of PCM. DI assay is high specific, but its sensitivity may vary between 65 to $100 \%$ depending on the antigenic preparation used $[3,12,15]$. Although the DI assay has advantages regarding cost and feasibility, the implementation of a faster and more sensitive test in the serological routine method is necessary. It could contribute to early initiation of appropriate therapy, which could prevent further damage and help in monitoring fungal dissemination to other organs.

In the past decades, many investigators have described the application of serological tests to the diagnosis of PCM. From the complement fixation test to the immunoenzymatic assays, there has been an increased interest in methodologies that are fast, simple to perform and inexpensive $[3,10,12]$. Dot-ELISA has been widely accepted as a rapid, versatile and simple test based on the principle of enzyme immunoassays, for the detection of many protozoan, virus and fungus diseases [16]. The use of Dot-ELISA for diagnosis of PCM was previously reported by three groups - namely Taborda and Camargo [17], Martins et al. [18] and Correa et al. [19] - without crucial differences in sensitivity and specificity. In all these tests, different reagents and antigenic non-standardized preparations were employed.

In order to improve the serological parameters for the diagnosis of PCM, the present study aimed to produce a fast and accurate method to detect anti-P. brasiliensis antibodies employing crude antigen (culture filtrate) and to evaluate the performance and applicability of Dot-
ELISA assay as a rapid screening test for the diagnosis of PCM, comparing it to the standard technique, double immunodiffusion.

\section{Methods}

\section{Serum samples}

A study was designed with a total of 443 serum samples obtained from March 2012 to June 2014 at the Laboratory of Mycosis Immunodiagnosis of Adolfo Lutz Institute and Department of Tropical Diseases of Botucatu Medical School, UNESP. Seventy-seven serum samples were from patients previously diagnosed with PCM (proven cases), by finding the etiologic agent in biological samples. Twenty-three serum samples from healthy individuals (normal human serum - NHS), sera from individuals with tuberculosis $(n=20)$ and sera with DI test confirming histoplasmosis $(\mathrm{n}=16)$ and aspergillosis $(n=8)$ were used as controls (non-PCM). Three hundred serum samples obtained from patients with "clinical suspicion" (probable and possible cases) of PCM were included in this study. The cases were classified following the Guideline on Paracoccidioidomycosis [20] and EORTC/MSG Consensus Group criteria (European Organization for Research and Treatment of Cancer/Mycosis Study Group) [21]. All samples were obtained from patients residing and domiciled in São Paulo state. Proven cases were from Botucatu region, probable and possible cases were from Campinas, Rio Claro, Sorocaba and São Paulo regions. Anti-P. brasiliensis polyclonal antibody, obtained in rabbits, was employed as positive control.

\section{Ethics consideration}

This study was approved by the Research Ethics Committee of Adolfo Lutz Institute, accession number 13673313.1.0000.0059.

\section{$P$. brasiliensis antigen}

The antigen used in this study was 20-day culture filtrate, obtained according to Silva et al. [22], from the yeast phase of B-339 P. brasiliensis (ATCC 32069TM) and $\mathrm{Pb}$ 113 strains. The fungi were cultured in NGTA - 3\% (w/v) neopeptone, $1.8 \%(\mathrm{w} / \mathrm{v})$ glucose, $0.009 \%(\mathrm{w} / \mathrm{v})$ asparagine, and $0.125 \%(\mathrm{w} / \mathrm{v})$ thiamine liquid medium for 20 days at $36{ }^{\circ} \mathrm{C}$ with shaking $(50 \mathrm{rpm})$. After incubation time, cultures were treated with an aqueous borate-thimerosal solution $(1: 5,000)$, and left to stand for $96 \mathrm{~h}$ at $4{ }^{\circ} \mathrm{C}$. After, supernatants were filtered through Whatman n. 1 paper, divided into small volumes and stored at $4{ }^{\circ} \mathrm{C}$ until use. Protein contents were subsequently assessed by the Bradford's method [23]. 


\section{Dot-ELISA assay}

The methodology was standardized according to the protocols described by Hawkes et al. [24] and Pappas [16] with some modifications. Dot-Elisa for detection of $P$. brasiliensis was performed on nitrocellulose membrane (NC) with $0.22 \mu \mathrm{m}$ pores (Bio-Rad Laboratories, USA) cut as $1 \times 1 \mathrm{~cm}$ squares. The absorption of the $P$. brasiliensis antigens to $\mathrm{NC}$ was performed by applying $6 \mu \mathrm{L}$ of each antigenic preparation in each square, followed by incubation for 30 minutes at $37{ }^{\circ} \mathrm{C}$. After drying, the free binding sites were blocked by $1 \mathrm{~h}$ incubation in PBS (pH7.4) containing 5\% non-fat dry milk (PBS-L 5\%), under continuous shaking at room temperature. These adsorbed and blocked membranes were stored at $8{ }^{\circ} \mathrm{C},-20^{\circ} \mathrm{C}$ and room temperature until use.

For antibody detection, membranes were placed on 24-well plate and then incubated for $2 \mathrm{~h}$ with $500 \mu \mathrm{L}$ of individual sera from patients with PCM, tuberculosis, histoplasmosis, aspergilosis and sera from healthy individuals diluted either 1:20, 1:40 or 1:100 in PBS containing 3\% non-fat dry milk (PBS-L 3\%), under continuous shaking at room temperature. After three washes with $500 \mu \mathrm{L}$ per well of $0.1 \%$ Tween-20 in PBS (PBS-T 0.1\%), membranes were immersed in solution of secondary antibody, goat anti-human IgG immunoglobulin conjugated with peroxidase (Sigma-Aldrich Co., USA), diluted 1:1,000 or 1:2,000 in PBS-L 3\%, for 90 minutes, at room temperature. After incubation, membranes were washed three times again. Then, membranes were immersed in a fresh solution containing $15 \mathrm{mg}$ of 4-chloro-1-naphtol (Sigma-Aldrich Co., USA) diluted in $5 \mathrm{~mL}$ of absolute methanol, $30 \mu \mathrm{L}$ of $30-\mathrm{vol}$ hydrogen peroxide and $20 \mathrm{~mL}$ Tris- $\mathrm{HCl} 0,5 \mathrm{M} \mathrm{pH}$ 6.8. The reaction was stopped by washing with distilled water. The NC squares were dried on filter paper and the development of blue dots was considered evidence of a positive result.

\section{Analysis of the membrane stability}

Nitrocellulose membranes previously sensitized with the P. brasiliensis antigen, were maintained at $-20{ }^{\circ} \mathrm{C}, 8{ }^{\circ} \mathrm{C}$ and room temperature and evaluated progressively for the antigenic reactivity over the time periods of 7,15 , 30, 45, 60 and 90 days, by DE with 11 serum samples randomly chosen among the 300 samples with clinical suspicion of PCM.

Three researchers with expertise in enzyme-linked immunosorbent assays such as immunoblotting (IB) and ELISA performed the analysis of anonymous serum sample. Samples were sequentially numbered avoiding identification of cases and controls by analysts. The DE assays were then performed on different days, including all the steps of the method. The test was carried out in duplicate to evaluate the intra- and inter-assay according to the content.

\section{Double immunodifusion assay}

Reactions were performed according to the modified Ouchterlony's method [25]. Glass slides were covered with $3.0 \mathrm{~mL}$ of $1 \%$ agarose gel type II medium (Sigma Chemical Co., USA) diluted in a buffered saline solution $\mathrm{pH} 6.9$ containing $0.4 \%$ sodium citrate and $7.5 \%$ glycine. Antigen $(12 \mu \mathrm{L})$ was placed in the central well, while control and patient sera $(12 \mu \mathrm{L})$ were added in surrounding wells. The slides were incubated in a humid chamber at room temperature for 48 hours. Then, they were washed with saline solution with several changes over a 24-hour period. Gels were dried and stained in $0.4 \%$ Coomassie brilliant blue R-250 (Sigma Chemical Co., USA) in an ethanol-acetic acid-water mixture as solvent.

\section{Statistical analysis}

The diagnostic accuracy of DE was evaluated by sensitivity (proportions of positive samples correctly identified by the test) and co-sensitivity (considering DI as the standard assay), specificity (proportions of negative samples correctly identified by the test) and co-specificity (considering DI as the standard assay), predictive values of Dot-ELISA test was determined and the main results were calculated according to Jacobson [26]. The agreement index of tests was calculated and classified by Kappa coefficient according to Landis and Koch [27]. Finally, for proportion comparison we used the chi-square test, performed by the Epi Info 6.1 program (Center for Disease Control and Prevention - http:// www.cdc.gov) with $\mathrm{p} \leq 0.05$ significance value.

\section{Results}

In order to standardize the Dot-ELISA assay, several experiments were performed to define the optimal conditions to improve this methodology. Conditions established were:

- Employment of culture filtrate obtained from the B339 strain of $P$. brasiliensis instead of culture filtrate obtained from $\mathrm{Pb} 113$ isolate.

- The optimal concentration of the antigen tested on the NC squares was $42 \mathrm{ng} / \mu \mathrm{L}$.

- A dilution of 1:100 of sera from patients with paracoccidioidomycosis, tuberculosis, histoplasmosis or aspergilosis and healthy individuals.

- A dilution of 1:2000 of secondary antibody labelled with peroxidase.

Positive reactions were visualized as spots varying from dark purplish blue (strongly reactive sera) to pale 
purplish blue (weakly reactive sera), depending on the intensity of the reaction. Results were considered negative when no color was observed (Fig. 1). The intrinsic parameters were calculated for both methodologies (DE and DI): sensitivity of $91 \%$ (70/77) and 72.7\% (56/77), specificity of $95.4 \%(63 / 66)$ and $98.5 \%(65 / 66)$, accuracy of $93 \%$ and $84.6 \%$ (121/143), positive and negative predictive values were $96 \%(70 / 73)$ and $98.2 \%(56 / 57)$, 90\% (63/70) and 75.6\% (65/86), respectively (Table 1$)$.

The performances of DE compared to that of DI standard method were evaluated using 300 samples from patients with clinical suspicion (probable and possible cases) of PCM. Anti-P. brasiliensis circulating antibodies were detected in $34 \%$ of samples using DI, while DE had detected these antibodies in $47.3 \%$ of samples. Discriminatory capacity of both methods suggested that DE assay has a tendency to increase the reactivity pattern, as it was recognized by 40 more samples $(13.3 \%)$ than DI. Co-positivity (relative sensitivity) and co-negativity (relative specificity) values, using the DI assay as the standard serological test, were 92\% (101/110) and 99.5\% (189/ 190) respectively, achieving an agreement level between them of $\mathrm{k}=0.93$, considered very good.

The reproducibility of the test has shown that the intra-observer and inter-observer were extremely satisfactory, since their duplicates kept equal both in the result itself (reactive, non-reactive or undetermined) and in the staining intensity.

The evaluation of the viability of previously sensitized nitrocellulose membranes with the B-339 antigen was performed by $\mathrm{DE}$ probed against the 11 serum samples from patients with PCM clinical suspicion (probable and possible cases). Reactivity was observed on the membranes up to 90 days.

\section{Discussion}

In Brazil, paracoccidioidomycosis has significant rates of mortality that are estimated to be between 2 and 23\% in severe cases, and can reach up to $30 \%$ when associated with AIDS [28]. In addition, it is considered the major cause of mortality among mycoses in the country with an average of 111.5 deaths/year [1, 6, 7], according to the Mortality Information System (Brazilian Ministry of
Table 1 Serological intrinsic parameters of double immunodiffusion test (DI) and Dot-ELISA technique (DE)

\begin{tabular}{lcc}
\hline & DI (\%) & DE (\%) \\
\hline Sensitivity & 72.7 & 91.0 \\
Specificity & 98.5 & 95.4 \\
Accuracy & 84.6 & 93.0 \\
PPV & 98.2 & 96.0 \\
NPV & 75.6 & 90.0 \\
\hline
\end{tabular}

PPV positive predicted value, $N P V$ negative predicted value

Health). The clinical diagnosis of this mycosis can be mistaken for others infectious diseases including those caused by Leishmania spp. and Mycobacterium tuberculosis. Based on these factors, it becomes clear that the establishment of an early and accurate diagnosis of PCM is necessary for effective and specific initiation of therapy. This measure will reduce the unnecessary use of drugs and empiric therapy, thereby minimizing the emergence of multidrug-resistant fungal strains.

Recently, there has been great interest in the implementation of fast inexpensive methodologies that could also present high rates of sensitivity and specificity in the immunodiagnosis of microbial and parasitic diseases. In this sense, the dot-ELISA assay has been described as an appropriate method for the detection of antibodies or antigens in different human and animal infectious diseases including paracoccidiodomycosis $[16-19,29,30]$.

The pioneering study of Taborda and Camargo [17] standardized the methodology for the detection of IgG anti-gp43 antibodies, employing glycosylated and deglycosylated purified gp43, in the diagnosis and follow-up of patients with PCM. The sensitivity and specificity of this assay was $100 \%$ when gp43 was treated with sodium metaperiodate. Martins et al. [18] using a mixture composed by culture filtrate and somatic antigens of P. brasiliensis yeast cells obtained $96.2 \%$ of sensitivity. Correa et al. [19] using the $27 \mathrm{kDa}$ recombinant antigen obtained $100 \%$ of sensitivity and $98 \%$ of specificity. More recently, Assunção [30] using recombinant gp43 (gp43 $\triangle \mathrm{Nt}$ ) in PCM immunodiagnosis, observed $100 \%$ of sensibility and specificity after sodium metaperiodate treatment.

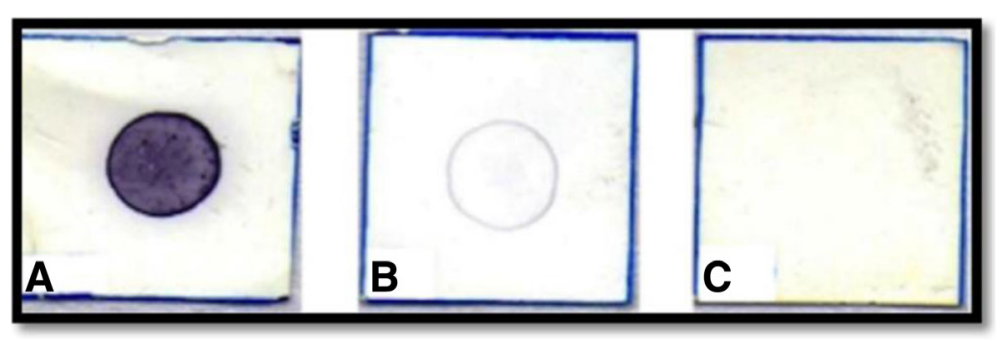

Fig. 1 Reactivity pattern of Dot-ELISA assay: (a) positive reaction, (b) undetermined reaction and (c) non-reactive result 
In the present study, employing culture filtrate obtained from B-339 P. brasiliensis strain in DE assay, we obtained $91 \%$ of sensitivity and $95.4 \%$ of specificity against $72.7 \%$ of sensitivity and $98.5 \%$ of specificity in DI. Statistical analysis, using chi-squared test, showed that $\mathrm{DE}$ technique was significantly more sensitive $(\mathrm{p}=$ 0.000067) than DI method, proving and enhancing the applicability of immunoenzymatic assays as optimal methodologies for serological screening.

The small distinct sensitivity observed in this study compared to other results - Taborda and Camargo [17], Martins et al. [18], Correa et al. [19] and Assunção [30] - might be related to differences in the standardization of the methodology, to the nature of the employed antigen, or due the fact that some samples presented no reaction by the DI assay, which indicates that patients were in clinical and/or serological cure. As stated by Perenha-Vianna et al. [31] there is an important limitation on antigenic preparations employed in serological methodologies that must be overcome. P. brasiliensis antigens are not commercially available and are usually obtained via in-house productions in research centers. Thus, the lack of standardization in protocols to obtain $P$. brasiliensis antigens causes large differences on test reproducibility.

Moreover, there is some evidence that support the use of crude antigen as immunobiological for anti- $P$. brasiliensis circulating antibody research, instead of $43 \mathrm{kDa}$ purified molecule due to the following: (i) gp43 presents several isoforms [32, 33]; (ii) $P$. brasiliensis expresses variable amounts of gp43 [34]; and (iii) levels of gp43 may vary according to the isolate [35]. Therefore, an individual infected with an isolate that produces gp43 at low rates will not present antibodies specific for this antigen at detectable concentrations, which proves the difficulty in using gp43 for the universal serological diagnosis of PCM [36].

Thus, the present study showed similar intrinsic parameter values of DE assay, using culture filtrate obtained from the B-339 strain of P. brasiliensis, when compared to those previously standardized, because it employed more specific and refined antigenic preparations. This finding has major advantages for public health laboratories, since obtaining the culture filtrate is significantly less costly and requires less complex procedures than those required to obtain purified and/ or recombinant antigens. Another point that deserves special attention is the good performance (in liters) and the excellent stability of the culture filtrate, more than 15 years after production [37]. Furthermore, we found that the use of culture filtrate also provides good index of sensitivity, specificity, accuracy, positive and negative predictive values, secured the intermediate repeatability and reproducibility of the Dot-ELISA assay.
In recent years, medical laboratories have undergone intense changes, especially regarding quality assurance of products offered. Hawkins [38] highlighted the significant number of publications that link the laboratory failures, estimated at $7-13 \%$, to the possibility of these occurring in the analytical phase. In the validation process, DE methodology was evaluated against 300 convenience samples, i.e. samples from individuals with clinical suspicion (probable and possible cases) of paracoccidioidomycosis. It was found that the relative sensitivity and relative specificity values, using the DI assay as the standard serological test, were $92 \%$ and $99.5 \%$, respectively, which achieved an agreement level between them of $\kappa=0.93$, considered great. In the present study, we also verified coherence in the interpretation of results between observers (intra and inter-observer). Comparison of DE methodology with different serologic assays has been thoroughly carried out by other authors $[16$, $39,40]$. It is unanimous that DE reaction is an excellent tool, primarily for seroepidemiological investigations, that is extremely adaptable in extra-laboratory settings and allows the evaluation of a high number of samples while using smaller amounts of antigen. Another important finding in this study relates to stability of nitrocellulose membranes endowed with the culture filtrate of $P$. brasiliensis.

Despite the good results obtained with membranes that were not blocked and stored at $-20{ }^{\circ} \mathrm{C}$, the best results were observed with membranes stored at room temperature up to 90 days (not blocked). Future studies should be conducted to assess the stability for longer periods. However, this finding opens the possibility of sending sensitized membranes to distant laboratories, enabling the realization of seroepidemiological surveys in settlements of people involved with rural activities or living in endemic areas. Historically, DI assay has been the technique of choice in the diagnosis of PCM, immunoenzymatic reactions such as ELISA and IB have also been used for the anti-P. brasiliensis antibodies detection [3, 10, 12, 22, 31, 41, 42]. However, despite showing good sensitivity the latter two have low specificity, and often require the previous adsorption of serum samples from patients with paracoccidioidomycosis with Histoplasma capsulatum or Candida albicans, dilution of serum in galactose or sodium metaperiodate antigen (gp43) treatment [43-45].

The Dot-ELISA proved to be extremely promising, versatile and can be applied as a serological screening test. Because of its high sensitivity as a methodology for the early diagnosis of the disease, it allows the release of negative results in less time than DI assay, i.e. one to seven days, which is of great diagnostic value, especially for the disposal of clinical suspicion of paracoccidioidomycosis. In addition, Dot-ELISA assay is less expensive 
than ELISA and IB, reagent conservative and does not require electrically powered instruments to give sensitive results. Its portability is ideal for use in field studies where the majority of immunodiagnostic assays are limited by their dependence on electricity, refrigeration or laboratorygrade water.

\section{Conclusions}

Given the numerous advantages of the presented methodology, this work proposes a broad discussion on the current algorithm recommended by the Epidemiological Surveillance Guide for Paracoccidioidomycosis of São Paulo State, proposing the replacement of indirect ELISA - currently recommended for the screening of serum samples - for Dot-ELISA.

\section{Abbreviations}

DE: Dot-ELISA; DI: double immunodiffusion; IB: immunoblotting;

NGTA: neopeptone, glucose, asparagine, thiamine;

PCM: paracoccidioidomycosis

\section{Acknowledgments}

We would like to thank Valdelene S. Kohara and Lúcia Cupertino Barreto for technical support. Thanks are also due to Marisa Ailin Hong for the careful review of the English.

\section{Funding}

The present study was supported by Adolfo Lutz Institute. CMK received a grant from the Coordination for the Improvement of Higher Education Personnel (CAPES)

\section{Authors' contributions}

CMK conducted the laboratory evaluations and drafted the first version of the manuscript. APV and RPM made a critical revision of the text. All authors read and approved the final manuscript.

\section{Competing interests}

The authors declare that they have no competing interests.

\section{Consent for publication}

Not applicable.

\section{Ethics approval and consent to participate}

The present study was approved by the Research Ethics Committee of Adolfo Lutz Institute, accession number 13673313.1.0000.0059.

\section{Author details}

'Laboratory of Mycosis Immunodiagnosis, Center of Immunology, Adolfo Lutz Institute, Av. Dr. Arnaldo, 355, 110 andar, sala 1117 São Paulo, SP, Brazil. ${ }^{2}$ Graduate Program in Sciences, Disease Control Coordination of the São Paulo State Health Secretariat, São Paulo, SP, Brazil. ${ }^{3}$ Department of Tropical Diseases, Botucatu Medical School, São Paulo State University (UNESP - Univ Estadual Paulista), Botucatu, São Paulo State, Brazil.

Received: 25 August 2016 Accepted: 8 February 2017

Published online: 15 February 2017

\section{References}

1. Colombo AL, Tobón A, Restrepo A, Queiroz-Telles F, Nucci M. Epidemiology of endemic systemic fungal infections in Latin America. Med Mycol. 2011:48(9):1-14.

2. Teixeira MM, Theodoro RC, Oliveira FF, Machado GC, Hahn RC, Bagagli E, et al. Paracoccidioides lutzii sp. nov:. biological and clinical implications. Med Mycol. 2014;52(1):19-28.

3. da Silva JF, de Oliveira HC, Marcos CM, Assato PA, Fusco-Almeida AM, Mendes-Giannini MJ. Advances and challenges in paracocidioidomycosis serology caused by Paracoccidioides species complex: an update. Diagn Microbiol Infect Dis. 2016;84(1):87-94.

4. Gonzalez A, Hernandez O. New insights into a complex fungal pathogen: the case of Paracoccidioides spp. Yeast. 2016;33(4):113-28. doi:10.1002/yea.

5. Martinez R. Epidemiology of paracoccidioidomycosis. Rev Inst Med Trop São Paulo. 2015;57(19):11-20

6. Coutinho ZF, da Silva D, Lazéra M, Petri V, de Oliveira RM, Sabroza PC, et al. Paracoccidioidomycosis mortality in Brazil (1980-1995). Cad Saúde Pública. 2002;18(5):1441-54.

7. Mendes RP. Paracoccidioidomycosis surveillance and control. J Venom Anim Toxins incl Trop Dis. 2010;16(2):194-7.

8. Marques SA. Paracoccidioidomycosis. Clin Dermatol. 2012;30(6):610-5.

9. Kamikawa CM, Kohara VS, Passos AN, Vicentini AP. Retrospective seroepidemiological analysis of patients with suspicion of paracoccidioidomycosis in São Paulo State, Brazil. J Venom Anim Toxins incl Trop Dis. 2012;18(3):264-71.

10. Teles FR, Martins ML. Laboratorial diagnosis of paracoccidioidomycosis and new insights for the future of fungal diagnosis. Talanta. 2011;85(5): 2254-64.

11. de Camargo ZP, de Franco MF. Current knowledge on pathogenesis and immunodiagnosis of paracoccidioidomycosis. Rev Iberoam Micol. 2000;17(2):41-8

12. de Camargo ZP. Serology of paracoccidioidomycosis. Mycopathologia. 2008; 165(4-5):289-302.

13. dos Santos PO, Rodrigues AM, Fernandes GF, da Silva SH, Burger E, Camargo ZP. Immunodiagnosis of paracoccidioidomycosis due to Paracoccidioides brasiliensis using a latex test: detection of specific antibody anti-gp43 and specific antigen gp43. PLoS Negl Trop Dis. 2015;9(2), e0003516.

14. Ferreira CS, Ribeiro EMC, Goes AM, Silva BM. Current strategies for diagnosis of paracoccidioidomycosis and prospects of methods based on gold nanoparticles. Future Microbiol. 2016;11:973-85.

15. Del Negro GMB, Garcia NM, Rodrigues EG, Cano IN, de Aguiar MSMV, Lirio VS, et al. The sensitivity, specificity and efficiency values of some serological tests used in the diagnosis of paracoccidioidomycosis. Rev Inst Med Trop S Paulo. 1991;33(4):277-80.

16. Pappas MG. Recent applications of the Dot-ELISA in immunoparasitology. Vet Parasitol. 1988:29(2-3):105-29.

17. Taborda CP, Camargo ZP. Diagnosis of Paracoccidioidomycosis by dot immunobinding assay for antibody detection using the purified and specific antigen gp43. J Clin Microbiol. 1994;32(2):554-6.

18. Martins R, Marques $S$, Alves M, Fecchio D, de Franco MF. Serological followup of patients with paracoccidioidomycosis treated with itraconazole using Dot-blot, ELISA and Western-blot. Rev Inst Med Trop São Paulo. 1997;39(5):261-9.

19. Correa MM, Bedoya AM, Guerrero MP, Méndez J, Restrepo A, McEwen JG. Diagnosis of paracoccidioidomycosis by a dot blot assay using a recombinant Paracoccidoides brasiliensis p27 protein. Mycoses. 2007:50(1):41-7.

20. Shikanai-Yasuda MA, Telles Filho FQ, Mendes RP, Colombo AL, Moretti ML. [Guidelines in paracoccidioidomycosis]. Rev Soc Bras Med Trop. 2006;39(3): 297-310 [Article in Portuguese].

21. de Pauw B, Walsh TJ, Donnelly JP, Stevens DA, Edwards J, Calandra T, et al. Revised definitions of invasive fungal disease from the European Organization for Research and Treatment of cancer/Invasive Fungal Infections Cooperative Group and the National Institute of Allergy and Infectious Diseases Mycoses Study Group (EORTC/MSG) Consensus Group. Clin Infect Dis. 2008;46(12):1813-21.

22. Silva DF, Assis CM, Zamboni IM, Barreto LC, Kohara VS, Vicentini-Moreira AP. Use of Immunoblotting assay improves the sensitivity of paracoccidioidomycosis diagnosis. J Venom Anim Toxins incl Trop Dis. 2008;14(2):314.

23. Bradford MM. A rapid and sensitive method for the quantitation of microgram quantities of protein utilizing the principle of protein-dye binding. Anal Biochem. 1976;72:248-54.

24. Hawkes R, Niday E, Gordon J. A Dot-Immunobinding assay for monoclonal and other antibodies. Anal Biochem. 1982;119(1):142-7.

25. Ouchterlony O. Antigen-antibody reactions in gels. Acta Pathol Microbiol Scand. 1949;26(4):507-15.

26. Jacobson RH. Validation of serological assays for diagnosis of infectious diseases. Rev Sci Tech. 1998;17(2):469-526. 
27. Landis JR, Koch GG. The Measurement of observer agreement for categorical data. Biometrics. 1977;33(1):159-74.

28. Morejón KM, Machado AA, Martinez R. Paracoccidioidomycosis in patients infected with and not infected with human immunodeficiency virus: a case control study. Am J Trop Med Hyg. 2009:80(3):359-66.

29. Kamikawa CM, Vicentini AP. Dot-blot methodology for rapid diagnosis of Paracoccidioidomycosis caused by Paracoccidioides brasiliensis. I Infect Dis Ther. 2015;3(6):2

30. Assunção TRS. Desenvolvimento de método para diagnóstico da paracoccidioidomicose humana utilizando antígeno recombinante de Paracoccidioides brasiliensis. [Dissertation]. Londrina: Universidade Estadual de Londrina - Centro de Ciências Biológicas; 2012. http://bdtd.ibict.br/ vufind/Record/UEL_7c909a3d0c438299b1b4165673993da2.

31. Perenha-Vianna MCZ, Gonzales IAA, Brockelt SR, Machado LNC, Svidzinski TIE. Serological diagnosis of Paracoccidioidomycosis through a Western Blot techinique. Clin Vaccine Immunol. 2012;19(4):616-9.

32. Puccia R, Schenkman S, Gorin PA, Travassos LR. Exocellular components of Paracoccidioides brasiliensis: identification of a specific antigen. Infect Immun. 1986;53(1):199-206.

33. Campos MC, Gesztesi JL, Vincentini AP, Lopes JD, Camargo ZP. Expression and isoforms of gp43 in different strains of Paracoccidioides brasiliensis. J Med Vet Mycol. 1995;33(4):223-7.

34. Berzaghi R, da Silva SH, de Camargo ZP. Variable gp43 secretion by Paracoccidioides brasiliensis clones obtained by two different culture methods. J Clin Microbiol. 2005;43(1):491-3.

35. Batista Jr J, de Camargo ZP, Fernandes GF, Vicentini AP, Fontes CJ, Hahn RC Is the geographical origin of a Paracoccidioides brasiliensis isolate important to antigen production for regional diagnosis of paracoccidioidomycosis? Mycoses. 2010;53(2):176-80.

36. Machado GC, Moris DV, Arantes TD, Silva LR, Theodoro RC, Mendes RP, et al. Cryptic species of Paracoccidioides brasiliensis: impact on paracoccidioidomycosis immunodiagnosis. Mem Inst Oswaldo Cruz. 2013; 108(5):637-43.

37. Silva DF. Analysis of Paracoccidioides brasiliensis exoantigens stability. J Venom Anim Toxins incl Trop Dis. 2006;12(4):657.

38. Hawkins R. Managing the Pre- and Post-analytical phases of total testing process. Ann Lab Med. 2012;32(1):5-16.

39. Sato H, Honigman AS, Scalarone GM. Development of a comparative dotELISA for the detection of antibodies in Blastomycosis. Diagn Microbiol Infect Dis. 1987;7(1):37-43.

40. Cervantes-Landín AY, Martínez-Martínez I, Reyes PA, Shabib M, EspinozaGutiérrez B. Estandarización de la tecnica Dot-ELISA para la detección de anticuerpos anti-Trypanosoma cruzi y su comparación con ELISA y Western blot. Enferm Infecc Microbiol Clin. 2014;32(6):363-8.

41. Sylvestre TF, Silva LRF, Cavalcante RS, Moris DV, Venturini J, Vicentini AP, et al. Prevalence and serological diagnosis of relapse in Paracoccidioidomycosis patients. PLoS Negl Trop Dis. 2014;8(5), e2834.

42. Bertoni TA, Perenha-Vianna MC, Patussi EV, Cardoso RF, Svidzinski TIE. Western blotting is an efficient tool for differencial diagnosis of Paracoccidioidomycosis and pulmonary tuberculosis. Clin Vaccine Immunol. 2012;19(11):1887-8.

43. Mendes-Giannini MJ, Camargo ME, Lacaz CS, Ferreira AW. Immunoenzymatic absorption test for serodiagnosis of paracoccidioidomycosis. J Clin Microbiol. 1984;20(1):103-8.

44. Albuquerque CF, Silva SH, Camargo ZP. Improvement of the specificity of an enzyme-linked immunosorbent assay for diagnosis of Paracoccidioidomycosis. J Clin Microbiol. 2005;43(4):1944-6.

45. Ferreira AP, Côrrea T, Cunha R, Marques MJ, Montesano MA, Souza MA, et al. Human serum antibody reactivity towards Paracoccidioides brasiliensis antigens treated with sodium metaperiodate. Rev Soc Bras Med Trop. 2008; 41(4):325-9.

\section{Submit your next manuscript to BioMed Central and we will help you at every step:}

- We accept pre-submission inquiries

- Our selector tool helps you to find the most relevant journal

- We provide round the clock customer support

- Convenient online submission

- Thorough peer review

- Inclusion in PubMed and all major indexing services

- Maximum visibility for your research

Submit your manuscript at www.biomedcentral.com/submit
C Biomed Central 